\title{
Correlation of clinical signs and symptoms of Behçet's disease with mean platelet volume (MPV) and red cell distribution width (RDW)
}

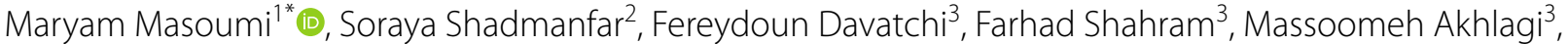 \\ Tahereh Faezi ${ }^{3}$, Hoda Kavosi ${ }^{3}$, Soroush Moradi ${ }^{2}$ and Javad Balasi ${ }^{4}$
}

\begin{abstract}
Background: A strong correlation was previously found between mean platelet volume (MPV), red blood cell distribution width (RDW), and the severity of signs and symptoms in patients suffering from inflammatory and autoimmune diseases. The current study evaluated these correlations in patients with Behçet's disease (BD) as well the relationship between MPV and RDW and disease activity score on the Iranian Behçet's Disease Dynamic Activity Measurement (IBDDAM).
\end{abstract}

Methods: This cross-sectional study included 319 patients with BD for whom demographic and epidemiological data, IBDDAM scores, and duration of illness was recorded. Blood samples were then obtained and the relationships between their disease status and manifestations and their laboratory parameters were evaluated with statistical models to find possible correlations.

Results: Our analysis showed a significantly higher RDW in patients with BD who had ocular manifestations $(p<0.001)$ and oral aphthae $(p=0.004)$. Patients with active BD had higher RDW $(p<0.001)$ and MPV $(p<0.001)$ in comparison to those with currently inactive BD. Similarly, patients who had any type of ocular manifestation had higher RDW $(p<0.001)$ and MPV $(p<0.001)$. Regression analyses identified a statistically significant model for the effect of RDW and MPV in predicting active BD status $(p<0.001)$, as well as its significant relationship with active ocular manifestations $(p<0.001)$.

Conclusion: BD was found to be associated with an increase in MPV and RDW, particularly during active phases. RDW and MPV were also found to have predictive value for screening to detect BD activity and its ocular complications.

Keywords: Behçet's disease, Mean platelet volume, Red blood cell distribution width, Uveitis, Ocular involvement

\section{Background}

Behçet's disease (BD) is a multisystemic, chronic, relapsing inflammatory disorder characterized by recurrent ulcerations and other clinical manifestations

\footnotetext{
${ }^{*}$ Correspondence: m.masoumiy@gmail.com; mmasoomi@muq.ac.ir ${ }^{1}$ Clinical Research and Development Center, Shahid Beheshti Hospital, Qom University of Medical Sciences, Beheshti Blvd, 3719964797 Qom, Qom, Iran

Full list of author information is available at the end of the article
}

[1]. The main clinical manifestations include involvement of the mucocutaneous, urogenital, locomotor, ocular, neurological, gastrointestinal, respiratory, and vascular systems $[2,3]$. Among these, ocular involvement is considered one of the most prevalent symptoms of BD $[4,5]$. Disease activity in BD is clinically assessed with several classification scales, including the Iranian Behçet's Disease Dynamic Activity Measurement (IBDDAM), which evaluates disease activity according to clinical findings during the preceding 12 months original author(s) and the source, provide a link to the Creative Commons licence, and indicate if changes were made. The images or other third party material in this article are included in the article's Creative Commons licence, unless indicated otherwise in a credit line to the material. If material is not included in the article's Creative Commons licence and your intended use is not permitted by statutory regulation or exceeds the permitted use, you will need to obtain permission directly from the copyright holder. To view a copy of this licence, visit http://creativecommons.org/licenses/by/4.0/. The Creative Commons Public Domain Dedication waiver (http://creativeco mmons.org/publicdomain/zero/1.0/) applies to the data made available in this article, unless otherwise stated in a credit line to the data. 
[6]. However, there is still a demand for novel laboratory markers, not only to determine disease activity in patients with $\mathrm{BD}$, but also to find potentially informative correlations with different signs and symptoms that can help to predict the disease course and prevent its exacerbation [7, 8]. As a result, biomarkers in blood samples from patients are currently receiving much attention in the search for possible correlations with diseases activity and its manifestations $[9,10]$.

In terms of its pathological manifestations BD represents a type of vasculitis; thanks to its specific clinical signs and symptoms, it is generally more easily diagnosed than other types of vasculitis since BD affects all vessels regardless of their size [11]. Although patients with BD may suffer from thrombosis-associated vascular involvement, the exact mechanism of thrombus formation remains unclear. A further consideration is that endothelial injury might not be solely responsible for the development of thrombosis, since several patients who have presented with thrombosis lacked endothelial injury [12]. Some studies suggested that platelet function correlates with the development of thromboses in patients with BD $[9,10]$. With an accurate determination of the relationship between platelet activity and morphological features such as volume, mean platelet volume (MPV) might be able to serve as a diagnostic marker to further study the role of platelets in thrombosis formation $[12,13]$.

Mean platelet volume (MPV) is an important indicator of platelet activation. It increases with an increase in thrombocyte production. Important alterations in volume parameters of thrombocytes may have prophylactic and diagnostic importance in thrombotic events and prothrombotic tendency. In addition, increments in the platelet volume causes ischemia and infarction [14].

Red blood cell distribution width (RDW) is another parameter proposed to be associated with inflammatory processes. However, its use is mostly limited to the diagnosis of anemia because it is a numerical measurement of red blood cell (RBC) heterogeneity in volume in complete blood counts $[15,16]$.

Several earlier studies have shown a strong correlation of MPV and RDW with the severity of patients' signs and symptoms, particularly in individuals suffering from inflammatory and autoimmune diseases including BD $[17,18]$. In addition, a few studies have evaluated these markers in patients with ocular manifestations of $\mathrm{BD}$ although none of them has investigated the relationship between MPV and RDW with disease activity based on activity measurement tools. Therefore, the present study was designed to compare MPV and RDW in patients with ocular BD and those with other manifestations, as well as the correlation of these measures with disease activity score according to the IBDDAM.

\section{Methods}

Patients diagnosed with BD were enrolled in this crosssectional study in consecutive order, regardless of the current activity state of their disease. Only drug-naive patients had been recruited in our study. Patients suffering from other autoimmune or inflammatory conditions, including but not limited to malignancies and endocrine diseases, were excluded from this study.

$\mathrm{BD}$ was diagnosed according to the ICBD criteria.

The Ethics Committee of Tehran University of Medical Sciences approved the study protocol, and all patients provided informed consent before participation. The IBDDAM questionnaire outcomes were used only for investigational purposes and had no impact on clinical decision making or treatment decisions.

The patients' demographics and clinical information including age, gender, duration of the disease, medications used (e.g. colchicine, prednisolone, cytotoxic drugs, and disease-modifying anti-rheumatic drugs [DMARDs]) were recorded, along with IBDDAM scores [21]. The patients' IBDDAM scores were obtained in two follow-up sessions, and the overall score was calculated by adding the scores from the two sessions and dividing the sum by the interval between the two sessions (in months). The IBDDAM score evaluates 11 clinical manifestations, including oral aphthae (one point per five ulcers), genital ulceration (one point per ulcer), pseudofolliculitis (one point per ten lesions), erythema nodosum (one point per five lesions), arthritis (arthralgia one point, monoarthritis two points, polyarthritis three points), venous involvement (thrombophlebitis one point, large vessel thrombosis two points), intestinal manifestations (three points for mild manifestations, six points for moderate to severe manifestations), central nervous system (CNS) manifestations (one point for mild headaches, three points for mild CNS involvement, six points for moderate to severe manifestation), epididymitis (two points), and pathergy (one point). Then blood samples were obtained to record complete blood count $(\mathrm{CBC})$ components. MPV and DW were also measured by same laboratories.

\section{Statistical analysis}

Continuous variables were reported as the mean \pm standard deviation (SD), and percentage and frequency values were used to report categorical data. Continuous and parametric data were compared between groups with an independent $t$-test, whereas categorical data were analyzed with the chi-squared test. A point-biserial correlation was run between $C B C$ parameters of MPV and RDW and the use of DMARDs. Preliminary analyses showed no outliers, as assessed by boxplot, and engagement score was normally distributed, as assessed by Shapiro-Wilk's test $(p>0.05)$. In 
addition, variances were homogeneous, as assessed by Levene's test for equality of variances.

Multiple regressions were run to predict the IBDDAM score from MPV and RDW. Linearity was found in partial regression plots and a plot of studentized residuals against the predicted values. The independence of residuals was verified by a Durbin-Watson statistic of 1.873 , and homoscedasticity was confirmed by visual inspection of a plot of studentized residuals versus unstandardized predicted values. No evidence of multicollinearity was found, given that the tolerance values were higher than 0.1 . There were no studentized deleted residuals greater than \pm 3 standard deviations, no leverage values greater than 0.2 , and values for Cook's distance were greater than 1 . The assumption of normality was met, as assessed by a Q-Q Plot.

Binomial logistic regression was used to ascertain the effects of MPV and RDW on the likelihood that participants had active BD and active ocular manifestation of the disease. Linearity of continuous variables for the logit of the dependent variable was assessed with the Box-Tidwell procedure. The sensitivity, specificity, area under the curve (AUC), and optimal cut-off values were determined with receiver operating characteristic (ROC) curves. All analyses were done with SPSS Statistics for Windows version 25.0 (IBM Corp., Armonk, NY, USA). A $p$ value less than 0.05 was considered statistically significant.

\section{Results}

Patients

Three hundred twenty patients with BD between 10 and 81 years old (mean age $43.5 \pm 12$ years) were enrolled. Of these, 142 patients (44.5\%) were female and 177 (55.5\%) were male. Their medical histories indicated that 157 patients used colchicine, 33 received prednisolone, and 130 underwent DMARD therapy with azathioprine (AZA) in 123 patients, methotrexate (MTX) in 97, and cyclosporine (CsA) in 16. Complete blood count showed average values of $88.01 \pm 7.20$ for MCV and $13.96 \pm 1.35$ for RDW.

\section{MPV and RDW in different BD manifestations}

The prevalence of different clinical manifestations of BD is summarized in Table 1. An independent-sample $t$-test was run to determine whether differences in RDW or MPV corresponded with the appearance of specific BD signs and symptoms. Analyses showed that RDW was significantly higher only in patients with ocular manifestations $(p<0.001)$ and oral aphthae $(p=0.004)$. This, however, was not the case for MPV, and no correlation was found between MPV and any disease signs or symptoms.

Laboratory test results were compared in patients taking different medications. In patients who were taking DMARDs, MPV was significantly higher than in patients who were not using this medication $(10.78 \pm 2.49$ vs. $10.17 \pm 2.05, p=0.02$ ). There was no statistically significant difference in RDW values between patients taking

Table 1 Mean platelet volume (MPV) and red blood cell distribution width (RDW) values according to different clinical manifestations of Behçet's disease

\begin{tabular}{|c|c|c|c|c|c|c|}
\hline BD manifestations & & Frequency (\%) & MPV (mean $\pm S D)$ & $p$ & $\mathrm{RDW}($ mean $\pm \mathrm{SD})$ & $p$ \\
\hline \multirow[t]{2}{*}{ Oral aphthae } & No & $4(1.3 \%)$ & $8.9 \pm 1.56$ & 0.94 & $13.05 \pm 0.31$ & 0.25 \\
\hline & Yes & 315 (98.7\%) & $10.45 \pm 2.26$ & & $13.97 \pm 1.36$ & \\
\hline \multirow[t]{2}{*}{ Genital aphthae } & No & 137 (42.9\%) & $10.42 \pm 2.17$ & 0.17 & $13.86 \pm 1.38$ & 0.04 \\
\hline & Yes & $182(57.1 \%)$ & $10.43 \pm 2.33$ & & $14.04 \pm 1.34$ & \\
\hline \multirow[t]{2}{*}{ Ocular } & No & $68(21.3 \%)$ & $10.35 \pm 1.98$ & 0.74 & $13.48 \pm 1.13$ & $<0.001$ \\
\hline & Yes & $251(78.7 \%)$ & $10.45 \pm 2.33$ & & $14.09 \pm 1.39$ & \\
\hline \multirow[t]{2}{*}{ Dermal } & No & $236(74 \%)$ & $10.38 \pm 2.28$ & 0.56 & $14.02 \pm 1.37$ & 0.18 \\
\hline & Yes & $83(26 \%)$ & $10.55 \pm 2.2$ & & $13.79 \pm 1.32$ & \\
\hline \multirow[t]{2}{*}{ Pathergy test } & No & $200(62.7 \%)$ & $10.41 \pm 2.27$ & 0.84 & $14.02 \pm 1.37$ & 0.33 \\
\hline & Yes & $119(37.3 \%)$ & $10.46 \pm 2.24$ & & $13.87 \pm 1.35$ & \\
\hline \multirow[t]{2}{*}{ Vascular } & No & $294(92.2 \%)$ & $10.41 \pm 2.24$ & 0.61 & $13.99 \pm 1.37$ & 0.19 \\
\hline & Yes & $25(7.8 \%)$ & $10.65 \pm 2.5$ & & $13.62 \pm 1.14$ & \\
\hline \multirow[t]{2}{*}{ Gastrointestinal } & No & 305 (95.6\%) & $10.43 \pm 2.27$ & 0.94 & $13.97 \pm 1.37$ & 0.6 \\
\hline & Yes & $14(4.4 \%)$ & $10.39 \pm 2.05$ & & $13.78 \pm 1.04$ & \\
\hline \multirow[t]{2}{*}{ CNS } & No & 315 (98.7\%) & $10.42 \pm 2.27$ & 0.1 & $13.96 \pm 1.36$ & 0.62 \\
\hline & Yes & $4(1.3 \%)$ & $10 \pm 0.3$ & & $13.57 \pm 0.25$ & \\
\hline
\end{tabular}


and not taking DMARDs $(14.11 \pm 1.39$ vs. $13.85 \pm 1.32$, $p=0.09$ ).

\section{Active BD manifestations}

The frequencies of different manifestations of active BD are listed in Table 2. One hundred sixty-one patients (50.4\%) were found to have active BD manifestations in their most recent examination. Among 109 (31.4\%) patients with active ocular involvement, anterior uveitis was observed in 94 (29.5\%), and posterior uveitis in 17 (5.4\%). Retinal vasculitis was seen in 58 (18.2\%) patients. Active oral aphthae were present in 59 patients (18.5\%), and genital aphthae were found in $9(2.8 \%)$. Patients with active BD had significantly higher RDW $(p<0.001)$ and MPV $(p<0.001)$ in comparison to patients without any active manifestation (Fig. 1). Similarly, patients who had ocular manifestations in any site of involvement had higher RDW $(p<0.001)$ and MPV $(p<0.001)$ (Fig. 2). The presence of other BD manifestations, however, was not associated with MPV or RDW values in comparisons of patients with active BD vs. those whose disease was in an inactive state.

\section{Predictive value of RDW and MPV for BD manifestations}

Separate binomial logistic regression analyses were used to determine whether RDW and MPV could indicate the likelihood of patients having active BD or having active ocular manifestations of the disease. The results

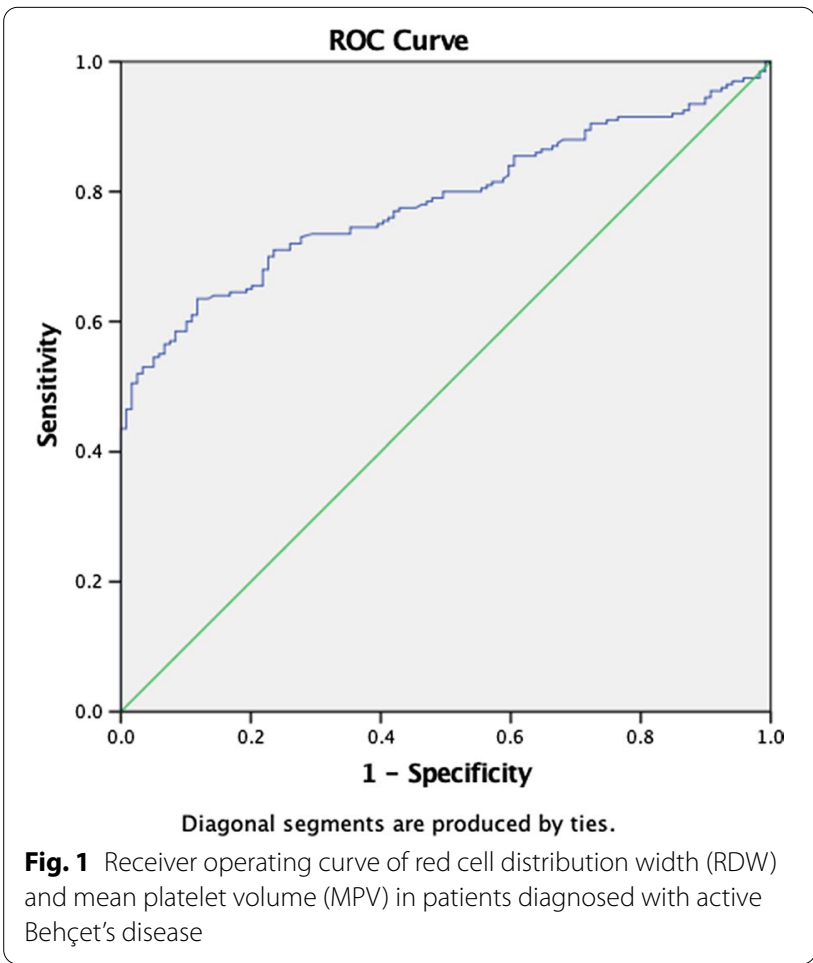

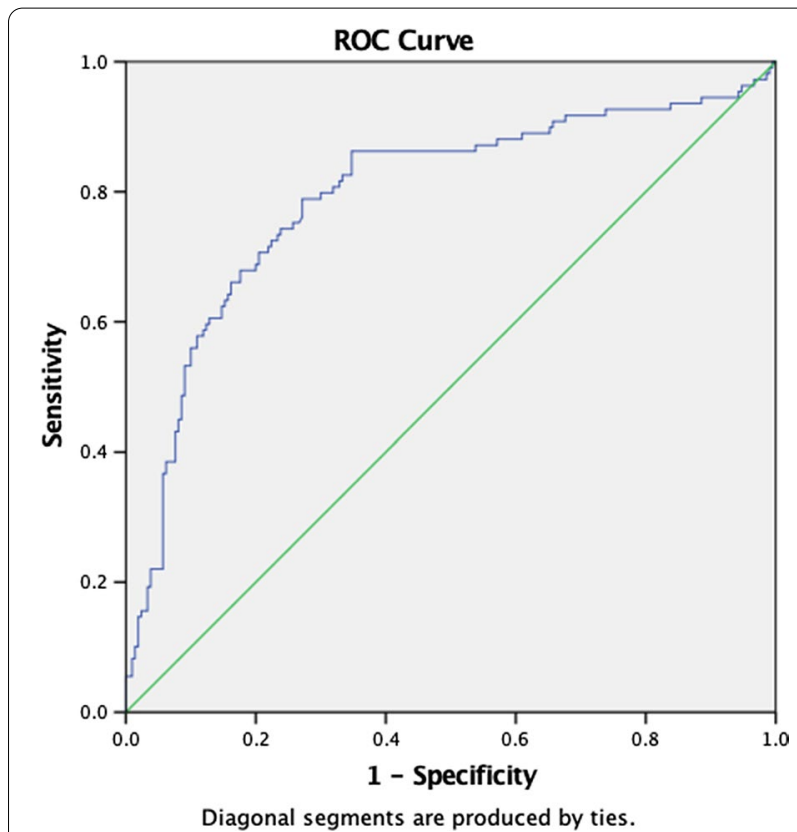

Fig. 2 Receiver operating curve of red cell distribution width (RDW) and mean platelet volume (MPV) in patients diagnosed with active ocular manifestations of Behçet's disease

produced a statistically significant logistic regression model in which the weight of RDW and MPV had some predictive power for active BD status, with $\chi^{2}(2)=82.205$ and $p<0.001$. The model explained $31.0 \%$ (Nagelkerke $\mathrm{R} 2$ ) of the variance in $\mathrm{BD}$, and correctly classified $68.3 \%$ of cases. Sensitivity was $80 \%$ and specificity was $51 \%$, with a positive predictive value of $62 \%$ and a negative predictive value of $71 \%$. Both of these two predictor variables were statistically significant (Table 3). Higher RDW and MPV were associated with a higher potential incidence of BD. The area under the ROC curve was 0.785 (95\% confidence interval [CI] 0.737-0.834), which is considered an acceptable level of discrimination.

The highest rates of sensitivity and specificity derived using Youden's J were found for the cut-off points of diagnostic accuracy for RDW and MPV. The RDW value of 14.15 showed $77 \%$ sensitivity and $65 \%$ specificity for the diagnosis of active BD. The cut-off value of MPV was 12.95 , with $73 \%$ sensitivity and $63 \%$ specificity.

The relationship between RDW and MPV and active ocular manifestations was evaluated with binomial logistic regression. The results yielded a statistically significant model, with $X^{2}(2)=76.948$ and $p<0.001$. The model explained $29.6 \%$ (Nagelkerke R2) of the variance in active ocular manifestations of BD, and correctly classified $77.7 \%$ of patients. Sensitivity was $53 \%$, specificity was $90 \%$, positive predictive value was $74 \%$, and negative predictive value was $79 \%$. In the predictive model, RDW and 
Table 2 Mean platelet volume (MPV) and red blood cell distribution width (RDW) values according to Behçet's disease activity status

\begin{tabular}{|c|c|c|c|c|c|c|}
\hline \multicolumn{2}{|c|}{ BD active manifestations } & \multirow{2}{*}{$\begin{array}{l}\text { Frequency (\%) } \\
119(37.4 \%)\end{array}$} & \multirow{2}{*}{$\begin{array}{c}\text { MPV (mean } \pm \text { SD) } \\
9.37 \pm 1.37\end{array}$} & \multirow{2}{*}{$\begin{array}{l}p \\
<0.001\end{array}$} & \multirow{2}{*}{$\begin{array}{l}\text { RDW (mean } \pm \text { SD) } \\
13.26 \pm 0.76\end{array}$} & \multirow{2}{*}{$\frac{p}{<0.001}$} \\
\hline Active BD & No & & & & & \\
\hline & Yes & $200(62.6 \%)$ & $11.05 \pm 2.45$ & & $14.38 \pm 1.47$ & \\
\hline \multirow[t]{2}{*}{ Active ocular signs } & No & $210(65.9 \%)$ & $9.82 \pm 1.84$ & $<0.001$ & $13.56 \pm 1.09$ & $<0.001$ \\
\hline & Yes & $109(34.1 \%)$ & $11.59 \pm 2.53$ & & $14.72 \pm 1.5$ & \\
\hline \multirow[t]{2}{*}{ Active oral signs } & No & $206(64.5 \%)$ & $10.38 \pm 2.3$ & 0.63 & $13.96 \pm 1.36$ & 0.63 \\
\hline & Yes & $113(35.5 \%)$ & $10.51 \pm 2.19$ & & $13.95 \pm 1.36$ & \\
\hline \multirow[t]{2}{*}{ Active genital signs } & No & $310(97.1 \%)$ & $10.47 \pm 2.26$ & 0.87 & $13.96 \pm 1.36$ & 0.46 \\
\hline & Yes & $9(2.9 \%)$ & $8.94 \pm 1.59$ & & $13.89 \pm 1.5$ & \\
\hline
\end{tabular}

$\mathrm{BD}$, Behçet's disease; MPV, mean platelet volume; RDW, red blood cell distribution width; SD, standard deviation

Table 3 Linear regression analysis of the correlation of mean platelet volume (MPV) and red blood cell distribution width (RDW) with Behçet's disease and ocular manifestations

\begin{tabular}{|c|c|c|c|c|c|c|c|c|c|}
\hline \multirow[t]{2}{*}{ Condition } & \multirow[t]{2}{*}{ Variable } & \multirow[t]{2}{*}{ B } & \multirow[t]{2}{*}{ SE } & \multirow[t]{2}{*}{ Wald } & \multirow[t]{2}{*}{ df } & \multirow[t]{2}{*}{$p$} & \multirow[t]{2}{*}{ Odds ratio } & \multicolumn{2}{|c|}{$\begin{array}{l}95 \% \mathrm{Cl} \text { for odds } \\
\text { ratio }\end{array}$} \\
\hline & & & & & & & & Lower & Upper \\
\hline \multirow[t]{3}{*}{ Active BD } & RDW & 0.709 & 0.131 & 29.362 & 1 & $<0.001$ & 2.031 & 1.572 & 2.625 \\
\hline & MPV & 0.32 & 0.07 & 21.221 & 1 & $<0.001$ & 1.378 & 1.202 & 1.579 \\
\hline & Constant & -12.472 & 1.893 & 43.392 & 1 & $<0.001$ & 0 & & \\
\hline \multirow[t]{3}{*}{ Ocular BD (active) } & RDW & 0.584 & 0.112 & 27.382 & 1 & $<0.001$ & 1.793 & 1.441 & 2.232 \\
\hline & MPV & 0.289 & 0.063 & 20.993 & 1 & $<0.001$ & 1.335 & 1.18 & 1.511 \\
\hline & Constant & -11.965 & 1.626 & 54.148 & 1 & $<0.001$ & 0 & & \\
\hline
\end{tabular}

BD, Behçet's disease; MPV, mean platelet volume; RDW, red blood cell distribution width; SD, standard deviation

MPV were statistically significant (Table 3), with higher values indicating the potential incidence of active ocular manifestations of BD. The area under the ROC curve was 0.794 (95\% CI 0.737-0.850), which was considered an acceptable level of discrimination. According to analysis with Youden's J, the cut-off values for a diagnosis of active ocular BD were 14.93 for RDW (62\% sensitivity and 92\% specificity), and 13.42 for MPV (52\% sensitivity and 90\% specificity).

\section{Relationship of RDW and MPV with IBDDAM score}

Multiple regressions were run to predict overall IBDDAM score from the patients' age, gender, body mass index (BMI), MPV, RDW, DMARD use, active BD status, active ocular signs, and active oral and genital ulcers. Six of the variables, e.g. age, gender, BMI, BD activity status, and active oral and genital aphthae, had no statistically significant role in the model. After omitting these variables from the predictive model, partial regression plots revealed linearity and yielded a plot of studentized residuals against the predicted values. The residuals were independent, according to the Durbin-Watson statistic of 1.925. The multiple regression model showed statistically significant predictive power for IBDDAM score,
Table 4 Summary of multiple regression analysis

\begin{tabular}{lclll}
\hline Variable & B & SE beta & Beta & $\boldsymbol{p}$ \\
\hline Intercept & 30.154 & 8.68 & & \\
RDW & 2.07 & 0.653 & 0.166 & 0.002 \\
MPV & 0.888 & 0.394 & 0.118 & 0.025 \\
Active ocular BD & 4.143 & 1.75 & 0.116 & 0.019 \\
DMARDs & 13.793 & 1.704 & 0.4 & 0.001 \\
\hline
\end{tabular}

$\mathrm{BD}$, Behçet's disease; DMARDs, disease-modifying anti-rheumatic drugs; MPV, mean platelet volume; RDW, red blood cell distribution width; $\mathrm{SE}$, standard error

with $\mathrm{F}(4,314)=26.06, p<0.001$, and adjusted $\mathrm{R}^{2}=0.24$. All four variables added statistically significant value to the prediction. The regression coefficients and standard errors are reported in Table 4.

\section{Discussion}

The present study aimed to investigate the correlation between two laboratory parameters which are easily obtainable from a blood sample and BD activity along with its different manifestations. RDW was significantly higher in patients with ocular and oral manifestations of $\mathrm{BD}$, regardless of disease activity. MPV, however, was not 
associated with clinical manifestations of BD. The results also demonstrated that RDW and MPV correlated with the activity of $\mathrm{BD}$, particularly in patients with ocular manifestations. According to Aksoy et al. study RDW were significantly higher in patients with Behçet's disease than in controls, and in those with active disease compared with inactive disease or controls. No differences were observed in RDW between patients with or without ocular or vascular involvement [19].

No such correlation was found between MPV or RDW and other BD signs and symptoms such as genital ulcers or vasculitis, probably because the incidence of these manifestations was low in our population sample. The area under the ROC curve indicated acceptable discriminative ability for RDW and MPV in differentiating active $\mathrm{BD}$ and active ocular manifestations of the disease. A linear correlation was also found between overall IBDDAM score and the aforementioned parameters.

Since its introduction, BD diagnosis has been based primarily on clinical assessment and physical examination, and no specific paraclinical findings or laboratory tests have been especially applicable in the process [20]. In response to the need for better diagnostic methods and in order to search for a link that connects paraclinical methods to disease activity, several biomarkers and factors have been identified as associated with $\mathrm{BD}$ activity, including platelet-to-lymphocyte ratio (PLR), neutrophil-to-lymphocyte ratio (NLR), and erythrocyte sedimentation rate (ESR) [21, 22]. Earlier studies have detected increased MPV and RDW in patients with inflammatory and chronic diseases, and researchers have speculated that these biomarkers might be associated with inflammation and pro-inflammatory processes [23$25]$. In this connection, RDW was found to correlate with levels of inflammation in rheumatoid arthritis, inflammatory bowel disease, and ankylosing spondylitis $[16,17$, $24,26]$. Furthermore, MPV has also been suggested as a biomarker associated with thrombosis and oral ulcers in patients with BD [27].

Since only a few studies have investigated the importance of these easily-applicable and inexpensive biomarkers in the clinical assessment of patients with BD, it has not been possible to use these biomarkers in clinical approaches. Nonetheless, our results show elevated RDW and MPV not only during BD flares but also in association with its ocular manifestations. Although the underlying etiology for this phenomenon is not well understood, we speculate that with the progression of pro-inflammatory states and the resulting disruption of erythropoiesis, secretion of inflammatory cytokines by platelets is enhanced, and an increase in RDW and MPV follows [12, 19]. Medication with DMARDs might also contribute to myelosuppression and result in disrupted CBC parameters such as RDW and MPV [28].

Several recent studies have noted a significant increase in RDW in patients with a history of BD regardless of disease activity [19, 29, 30]. Uzkeser et al. found increased MPV in patients with BD compared to a healthy control group, along with a significant positive correlation between MPV and BD manifestations such as oral and genital ulcers, ocular involvement, and arthritis [31]. In contrast, we found no significant association between active oral and genital aphthae and MPV; however, we did find that MPV correlated with ocular involvement in $\mathrm{BD}$. These contrasting results might be due to the low incidence of involvement of other organs in BD in the present study population.

In 2013, Turkcu et al. claimed that MPV measurement had no predictive value in determining the likelihood clinical improvement in ocular BD after standard immunosuppressive treatment [32]. Although we found no significant difference in MPV values between patients with and without ocular BD, the results of our study show not only a correlation between MPV and DMARD use, but also increased MPV in patients with active ocular involvement.

To our knowledge, our study is one of the first to evaluate RDW and MPV changes in patients with BD in connection with their disease activity and current manifestations. Additionally, we assessed the possible relationships of BD flares with demographic and laboratory characteristics, although in line with previous studies, no significant correlations could be found [9].

Aksoy et al. reported in 2015 that MPV was not elevated in patients with $\mathrm{BD}$ compared to healthy individuals, or in patients with active BD compared to patients with inactive $\mathrm{BD}$, despite finding higher MPV values in patients with vascular involvement than those without [19].

It is well established that platelets play an essential role in various inflammatory diseases by stimulating immune responses and activating immune cells, which is in line with our finding of significantly higher MPV values in patient with $\mathrm{BD}$, among whom the increase was higher in patients with active BD.

The present findings point to MPV and RDW as potentially promising clinical tools in the diagnosis of $\mathrm{BD}$, particularly in its active period. In addition, MPV and RDW might be applicable as screening parameters in patients with $\mathrm{BD}$, although this requires further comprehensive research with prospective studies and randomized trials.

In light of the present results and previous finding regarding specific associations of NLR and PLR with the active phase of $\mathrm{BD}$, we recommend further investigation 
into the correlation of PLR and NLR ratios with different clinical manifestations of Behçet's disease.

\section{Limitations}

The present study was not without limitations. Because it was carried out at a single center and conducted with a cross-sectional study design rather than a cohort design, our results provide some evidence for the applicability of MPV and RDW as a variables able to predict the disease course and its manifestations, yet further studies are required to test these parameters and establish them as valuable tools for the diagnosis and monitoring of patients with BD. Another limitation of our study was that laboratory tests were done only once for each patient regardless of their clinical status or disease activity. In addition, the absence of data on dietary habits limited our results. Finally, because of the low incidence of some signs and symptoms of BD in our study population, we were not able to evaluate the involvement of all organs with the same level of reliability.

\section{Conclusion}

BD was found to be associated with an increase in MPV and RDW, particularly during active phases. RDW and MPV were also found to have predictive value for screening to detect BD activity and its ocular complications.

\section{Acknowledgements}

We thank K. Shashok (AuthorAID in the Eastern Mediterranean) for improving the use of English in the manuscript.

\section{Authors' contributions}

SS, MM, FD, FS, MA, TF, and HK conceived and planned the visits. SS, MM, and FD carried out the physical examinations. SS and MM planned and carried out the laboratory tests. FD, FS, TF, HK, and MA contributed to analysis of the results. SS, MM, TF, HK, MA, and FD contributed to the interpretation of the results. MM and SM and JB took the lead in writing the manuscript. All authors provided critical feedback and helped shape the research, analysis and manuscript. All authors read and approved the final manuscript.

\section{Funding}

None declared.

\section{Availability of data and materials}

The datasets used and analyzed in the current study are available from the corresponding author on reasonable request.

\section{Ethics approval and consent to participate}

The Ethics Committee of Tehran University of Medical Sciences approved the study protocol, and all patients provided informed consent before participating.

\section{Consent for publication}

Not applicable.

\section{Conflict of interest}

The authors declare that they have no competing interests.

\section{Author details}

${ }^{1}$ Clinical Research and Development Center, Shahid Beheshti Hospital, Qom University of Medical Sciences, Beheshti Blvd, 3719964797 Qom, Qom, Iran.

${ }^{2}$ Tehran University of Medical Sciences, Tehran, Iran. ${ }^{3}$ Rheumatology Research
Center, Tehran University of Medical Sciences, Tehran, Iran. ${ }^{4}$ Student Research Committee, School of Medicine, Iran University of Medical Sciences, Tehran, Iran

Received: 25 April 2020 Accepted: 13 October 2020

Published online: 21 October 2020

\section{References}

1. Cho SB, Cho S, Bang D. New insights in the clinical understanding of Behçet's disease. Yonsei Med J. 2012;53(1):35-42.

2. Emmi G, Becatti M, Bettiol A, Hatemi G, Prisco D, Fiorillo C. Behçet's syndrome as a model of thrombo-inflammation: the role of neutrophils. Front Immunol. 2019;10:1085.

3. Davatchi F, Assaad-Khalil S, Calamia K, Crook J, Sadeghi-Abdollahi B, International Team for the Revision of the International Criteria for Behçet's Disease (ITR-ICBD), et al. The International Criteria for Behçet's Disease (ICBD): a collaborative study of 27 countries on the sensitivity and specificity of the new criteria. J Eur Acad Dermatol Venereol. 2014;28(3):338-47.

4. Bertrand P-J, Jamilloux Y, Ecochard R, Richard-Colmant G, Gerfaud-Valentin M, Guillaud M, et al. Uveitis: autoimmunity... and beyond. Autoimmun Rev. 2019:18:102351.

5. Ozyazgan Y, Ucar D, Hatemi G, Yazici Y. Ocular involvement of Behçet's syndrome: a comprehensive review. Clin Rev Allergy Immunol. 2015;49(3):298-306.

6. Shahram F, Khabbazi A, Nadji A, Ziaie N, Banihashemi AT, Davatchi F. Comparison of existing disease activity indices in the follow-up of patients with Behcet's disease. Mod Rheumatol. 2009:19(5):536-41.

7. Hu C-J, Pan J-B, Song G, Wen X-T, Wu Z-Y, Chen S, et al. Identification of novel biomarkers for Behcet disease diagnosis using human proteome microarray approach. Mol Cell Proteomics. 2017;16(2):147-56.

8. Seyahi E. Behçet's disease: how to diagnose and treat vascular involvement. Best Pract Res Clin Rheumatol. 2016:30(2):279-95.

9. Macey M, Hagi-Pavli E, Stewart J, Wallace GR, Stanford M, Shirlaw P, et al. Age, gender and disease-related platelet and neutrophil activation ex vivo in whole blood samples from patients with Behcet's disease. Rheumatology. 2011;50(10):1849-59.

10. Pamuk GE, Pamuk ÖN, Örüm H, Demir M, Turgut B, Cakir N. Might platelet-leucocyte complexes be playing a role in major vascular involvement of Behçet's disease? A comparative study. Blood Coagul Fibrinolysis. 2010;21(2):113-7.

11. Balta I, Balta S, Demirkol S, Ekiz O. Peripheral arterial disease in patients with Behçet's disease. Rheumatol Int. 2014;34(4):589-90.

12. Acikgoz N, Karincaoglu Y, Ermis N, Yagmur J, Atas H, Kurtoglu E, et al. Increased mean platelet volume in Behçet's disease with thrombotic tendency. Tohoku J Exp Med. 2010;221(2):119-23.

13. Yuri-Gasparyan A, Ayvazyan L, Mikhailidis PD, Kitas DG. Mean platelet volume: a link between thrombosis and inflammation? Curr Pharm Des. 2011;17(1):47-58.

14. Ayer M, Menken I, Yamak M, Ayer FA, Kırkızlar O, Burak AM. The impact of mean platelet volume (MPV) and JAK-2 mutation on thrombosis in chronic myeloproliferative diseases. Indian J Hematol Blood Transfus. 2017;33(2):181-7.

15. Song CS, Park DI, Yoon MY, Seok HS, Park JH, Kim HJ, et al. Association between red cell distribution width and disease activity in patients with inflammatory bowel disease. Dig Dis Sci. 2012;57(4):1033-8.

16. Hu Z-D, Chen Y, Zhang L, Sun Y, Huang Y-L, Wang Q-Q, et al. Red blood cell distribution width is a potential index to assess the disease activity of systemic lupus erythematosus. Clin Chim Acta. 2013;425:202-5.

17. Cakal B, Akoz AG, Ustundag Y, Yalinkilic M, Ulker A, Ankarali H. Red cell distribution width for assessment of activity of inflammatory bowel disease. Dig Dis Sci. 2009;54(4):842-7.

18. Kisacik B, Tufan A, Kalyoncu U, Karadag O, Akdogan A, Ozturk MA, et al. Mean platelet volume (MPV) as an inflammatory marker in ankylosing spondylitis and rheumatoid arthritis. Joint Bone Spine. 2008;75(3):291-4.

19. Aksoy ŞN, Savaş E, Sucu M, Kisacik B, Kul S, Zengin O. Association between red blood cell distribution width and disease activity in patients with Behçet's disease. J Int Med Res. 2015;43(6):765-73. 
20. Davatchi F. How to diagnose Behcet's disease. J Immunol Res. 2014;1 (1):2.

21. Alan S, Tuna S, Türkoğlu EB. The relation of neutrophil-to-lymphocyte ratio, platelet-to-lymphocyte ratio, and mean platelet volume with the presence and severity of Behcet's syndrome. Kaohsiung J Med Sci. 2015;31(12):626-31.

22. Kim B, Park SJ, Hong SP, Cheon JH, Kim TI, Kim WH. Overlooked management and risk factors for anemia in patients with intestinal Behcet's disease in actual clinical practice. Gut Liver. 2015;9(6):750.

23. Yazici S, Yazici M, Erer B, Erer B, Calik Y, Ozhan H, et al. The platelet indices in patients with rheumatoid arthritis: mean platelet volume reflects disease activity. Platelets. 2010;21(2):122-5.

24. Hu Z-D, Sun Y, Guo J, Huang Y-L, Qin B-D, Gao Q, et al. Red blood cell distribution width and neutrophil/lymphocyte ratio are positively correlated with disease activity in primary Sjögren's syndrome. Clin Biochem. 2014;47(18):287-90.

25. Tecer D, Sezgin M, Kanık A, İncel NA, Çimen ÖB, Biçer A, et al. Can mean platelet volume and red blood cell distribution width show disease activity in rheumatoid arthritis? Biomark Med. 2016;10(9):967-74.

26. Lee WS, Kim T-Y. Relation between red blood cell distribution width and inflammatory biomarkers in rheumatoid arthritis. Arch Pathol Lab Med. 2010;134(4):505-6.

27. Ekiz O, Balta I, Sen BB, Rifaioglu EN, Ergin C, Balta S, et al. Mean platelet volume in recurrent aphthous stomatitis and Behçet disease. Angiology. 2014;65(2):161-5.
28. Ishchenko A, Lories RJ. Safety and efficacy of biological disease-modifying antirheumatic drugs in older rheumatoid arthritis patients: staying the distance. Drugs Aging. 2016;33(6):387-98

29. Vayá A, Hernández V, Rivera L, Hernández JL, Lago A, España F, et al. Red blood cell distribution width in patients with cryptogenic stroke. Clin Appl Thromb Hemost. 2015;21(3):241-5.

30. Gheita T, Sakr B, Rabea R, ElHamid SA. Value of hematological indices versus VEGF as biomarkers of activity in Behçet's disease. Clin Rheumatol. 2019. https://doi.org/10.1007/s10067-019-04513-5.

31. Uzkeser H, Haliloglu S, Cayir Y, Bilen N, Karaaslan Y, Kosar A, et al. Is mean platelet volume a new activity criteria in Behçet's disease? Blood Coagul Fibrinolysis. 2015;26(7):836-9.

32. Türkcü $F M$, Cingü $A K$, Yüksel $H$, Çınar $Y$, Akkurt $M$, Şahin $M$, et al. Mean platelet volume in ocular Behçet's disease. Sci World J. 2013. https://doi. org/10.1155/2013/215912.

\section{Publisher's Note}

Springer Nature remains neutral with regard to jurisdictional claims in published maps and institutional affiliations.
Ready to submit your research? Choose BMC and benefit from:

- fast, convenient online submission

- thorough peer review by experienced researchers in your field

- rapid publication on acceptance

- support for research data, including large and complex data types

- gold Open Access which fosters wider collaboration and increased citations

- maximum visibility for your research: over $100 \mathrm{M}$ website views per year

At BMC, research is always in progress.

Learn more biomedcentral.com/submissions 